\title{
Studies on the Radical Polymerization of Methyl Methacrylate in Bulk and in Benzene Using Totally Deuterated Monomer Technique
}

\author{
Koichi HatadA, Tatsuki KitAyama, and Eiji MASUDA \\ Department of Chemistry, Faculty of Engineering Science, \\ Osaka University, Toyonaka, Osaka 560, Japan
}

(Received December 3, 1985)

\begin{abstract}
Totally deuterated methyl methacrylate (MMA- $d_{8}$ ) was polymerized with AIBN in bulk at $60^{\circ} \mathrm{C}$, and the resultant polymer was analyzed for the initiator fragment by ${ }^{1} \mathrm{H} \mathrm{NMR}$ spectroscopy. Amount of the AIBN fragment at the beginning of the chain was found to be 1.15 per molecule, indicating $85 \%$ of the polymer molecules formed through disproportionation reaction. NMR analysis of the undeuterated PMMA prepared under the same conditions showed that the polymer contained 0.36 vinylidene double bond at the chain end. This is consistent with the results obtained from the P (MMA- $d_{8}$ ). P (MMA- $d_{8}$ ) prepared with BPO in benzene at $60^{\circ} \mathrm{C}$ had 1.20 initiator fragment per chain, $82 \%$ of which was phenyl group and $18 \%$ benzoyloxy one. Polymerizations in benzene with AIBN in the presence and absence of thiophenol were also examined.

KEY WORDS Methyl Methacrylate / Methyl Methacrylate Radical

Polymerization / Mechanism of Termination Reaction / Disproportionation /

Thiophenol / End Group Analysis / Deuterated Methyl Methacrylate /

Azobisisobutyronitrile / Benzoyl Peroxide / NMR /
\end{abstract}

Analysis of initiator fragments at the end of polymer chain is a straightforward method for understanding the mechanism of polymerization. It has been demonstrated utilizing ${ }^{14} \mathrm{C}$ labeled $\alpha, \alpha^{\prime}$-azobisisobutyronitrile (AIBN) that polystyrene radicals terminate exclusively by combination at the temperature up to $60^{\circ} \mathrm{C}$ while PMMA radicals undergo substantial disproportionation. ${ }^{1,2}$ However, the use of ${ }^{14} \mathrm{C}$ labeled initiator only gives information on the number of initiator fragments and is not sensitive to how the fragment is incorporated into the polymer chain. Recently NMR studies were carried out to examine the end group of a polymer chain using a ${ }^{13} \mathrm{C}-,{ }^{3-9}{ }^{2} \mathrm{H}-,{ }^{8,10}{ }^{19} \mathrm{~F}-,{ }^{11}$ or ${ }^{15} \mathrm{~N}$-labeled ${ }^{8}$ initiator. The NMR methods enable us to determine not only the number but also the structures of initiator fragments.

We have studied the mechanism of radi- cal, ${ }^{12-14}$ cationic, ${ }^{15}$ and anionic ${ }^{16-19}$ polymerizations by the totally deuterated monomer technique where the totally deuterated monomer is polymerized with undeuterated initiator and the resulting polymer is studied by ${ }^{1} \mathrm{H}$ NMR spectroscopy. In the previous communication $^{12}$ totally deuterated MMA (MMA- $d_{8}$ ) was polymerized in toluene with undeuterated AIBN and benzoyl peroxide (BPO) and the relative importance of disproportionation and combination in termination reaction was estimated from the ${ }^{1} \mathrm{H}$ NMR spectra of the polymers. In this work MMA- $d_{8}$ was polymerized under several conditions with AIBN and BPO, and the resultant polymers were analyzed in detail by ${ }^{1} \mathrm{H}$ NMR spectroscopy. The amount of olefinic double bond at the end of the chain, which was formed through disproportionation reaction, was also analyzed by ${ }^{1} \mathrm{H}$ NMR spec- 
troscopy. From the results the mechanism of initiation and termination is discussed in some detail.

\section{EXPERIMENTAL}

MMA- $d_{8}$ was prepared from acetone cyanohydrin- $d_{7}$ and methanol- $d_{4},{ }^{20}$ and purified by fractional distillation under nitrogen pressure. The distillate was dried over calcium dihydride and then vacuum-distilled. The degrees of deuteration for $\alpha$-methyl, vinylidene methylene and methoxy methyl groups were found to be $99.4 \%, 99.5 \%$, and $99.7 \%$, respectively, by precision coaxial tubing method. ${ }^{21}$ MMA was obtained commercially and purified similarly to MMA- $d_{8}$. Benzene was purified by the usual manner and distilled over sodium under nitrogen pressure. The distillate was dried with butyllithium and redistilled under high vacuum. Cobalt-tetraphenylporphine complex was prepared according to the literature. ${ }^{22}$

Polymerization was carried out in a sealed glass ampoule under nitrogen pressure and the reaction mixture was poured into a large amount of methanol to precipitate the polymer formed. The precipitate was collected by filtration, washed several times with methanol and dried in vacuo at $60^{\circ} \mathrm{C}$. Polymerization was also carried out in the presence of thiophenol to prepare the polymer without carbon-carbon double bond at the chain end.

The ${ }^{1} \mathrm{H}$ NMR spectra of the polymer were taken in nitrobenzene- $d_{5}$ on a JNM-FX100 $(100 \mathrm{MHz})$ and a JNM-GX270 (270 MHz) Fourier transform NMR spectrometer (JEOL) at $110^{\circ} \mathrm{C}$ using hexamethyldisiloxane (HMDS) as the internal standard. The hydrogen content of the deuterated polymer sample was calculated from the ratio of the signal intensity of interest to the signal due to the remaining protons in nitrobenzene- $d_{5}$ used as a solvent for the measurement. The content of the remaining protons in nitrobenzene- $d_{5}$ was determined using precision coaxial tubing method. $^{21}$
The amount of vinylidene protons at the chain end of undeuterated PMMA was evaluated from the intensity ratio of their signals at 5.4 and $6.14 \mathrm{ppm}$ ( $c f$. Figure 2) to the ${ }^{13} \mathrm{C}$ satellite of methoxy proton resonance at 3.33 and $3.87 \mathrm{ppm}$ in the spectrum measured in deuterated chloroform at $55^{\circ} \mathrm{C}$.

The number average molecular weight of the polymer was measured in toluene at $60^{\circ} \mathrm{C}$ on a Hitachi 117 vapor pressure osmometer.

\section{RESULTS AND DISCUSSION}

MMA- $d_{8}$ was polymerized in bulk at $60^{\circ} \mathrm{C}$ with AIBN and the results are shown in Table I. Figure 1 shows the ${ }^{1} \mathrm{H}$ NMR spectrum of the polymer measured in nitrobenzene- $d_{5}$ at $110^{\circ} \mathrm{C}$. Besides the signals due to the remaining protons in the monomeric units, two peaks of equal intensity were observed at 1.23 and 1.31 ppm. These two peaks showed the ${ }^{1} \mathrm{H}$ spinlattice relaxation times, $T_{1} \mathrm{~s}$ of $1.0 \mathrm{~s}$ and disappeared when the polymer was prepared with BPO. These indicate that the signals are due to the methyl protons of the initiator fragment, 1cyano-1-methylethyl group located at the beginning of the chain. The $T_{1}$ value eliminates the possibility that the peaks arise from contaminants of small molecules $\left(T_{1} \simeq 10 \mathrm{~s}\right)$ or the protons of the groups within polymer chain ( $T_{1} \simeq 0.1 \mathrm{~s}$ ). The splitting into two peaks is due to the adjacent asymmetric carbon in the polymer chain. The content of the initiator fragments was measured to be $0.0298 \mathrm{mmol} / \mathrm{g}$ polymer, from which the number of fragments per polymer molecule was calculated to be 1.15. The precision of the measurements for five determinations was $2.7 \%$.

It is well known that chain transfer reaction to initiator is of no importance in the polymerization of MMA with AIBN. The transfer constant to the MMA monomer is of the order of $10^{-5}$; that is, one transfer reaction to the monomer occurs for $10^{5}$ propagation reactions. The degree of polymerization of the polymer is less than $4 \times 10^{2}$; therefore, transfer 
Studies on Radical Polymn of MMA Using MMA- $d_{8}$

Table I. Polymerization of MMA- $d_{8}$ by AIBN and BPO at $60^{\circ} \mathrm{C}$

\begin{tabular}{|c|c|c|c|c|c|c|c|}
\hline \multirow{2}{*}{ No. } & \multicolumn{2}{|c|}{ Initiator } & \multirow{2}{*}{$\frac{\mathrm{MMA}^{-d_{8}}}{\mathrm{moll}^{-1}}$} & \multirow{2}{*}{ Solvent } & \multirow{2}{*}{$\frac{\text { Yield }}{\%}$} & \multirow{2}{*}{$M_{n}^{\mathrm{a}}$} & \multirow{2}{*}{$\frac{\text { Initiator fragment }^{\mathrm{b}}}{\mathrm{mol} \mathrm{mol}^{-1}}$} \\
\hline & & $\mathrm{moll}^{-1}$ & & & & & \\
\hline 1 & AIBN & 0.37 & 9.32 & None & 23.4 & 38600 & 1.15 \\
\hline 2 & AIBN & 0.01 & 1.00 & Benzene & 35.4 & 38850 & $1.13_{5}$ \\
\hline $3^{c}$ & AIBN & 0.0046 & 0.92 & Benzene & 8.3 & 1400 & $0.97^{d}$ \\
\hline 4 & BPO & 0.0091 & 0.91 & Benzene & 30.0 & 47500 & 1.20 \\
\hline $5^{e}$ & AIBN & 0.37 & 9.36 & None & 24.4 & 44600 & - \\
\hline
\end{tabular}

a Determined by the vapor pressure osmometer.

b Represents the number of initiator fragments per polymer molecule.

c Polymerization was carried out in the presence of thiophenol $\left(0.046 \mathrm{moll}^{-1}\right)$.

d Represents the number of thiophenol fragments. The number of AIBN fragments was 0.02.

e Undeuterated MMA was used.

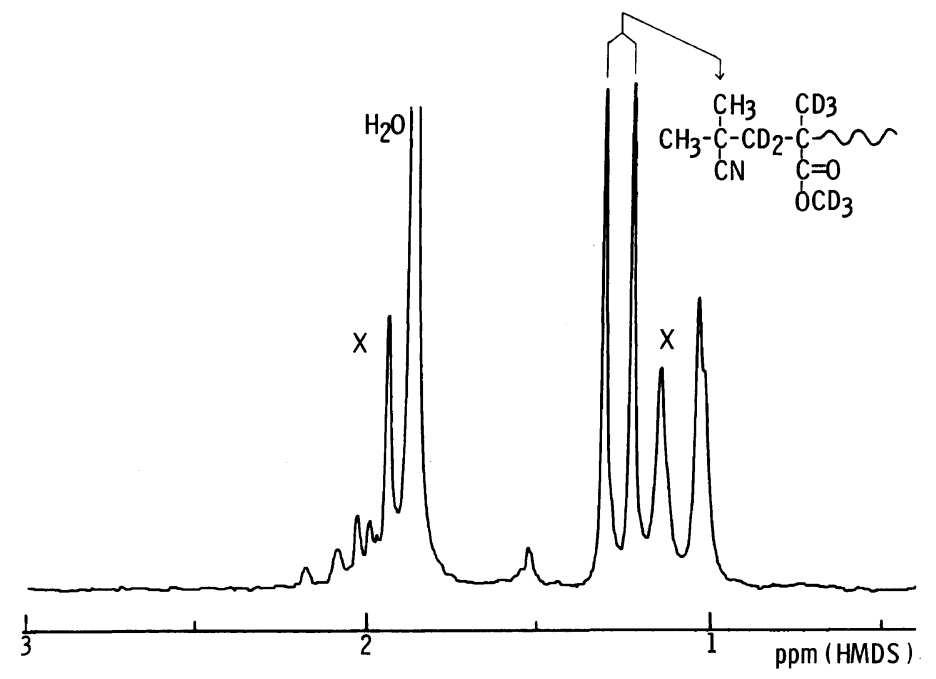

Figure 1. ${ }^{1} \mathrm{H}$ NMR spectrum of poly(MMA- $d_{8}$ ) prepared in bulk by AIBN at $60^{\circ} \mathrm{C}$ (nitrobenzene- $d_{5}$, $110^{\circ} \mathrm{C}, 100 \mathrm{MHz}$ ). The signals labeled $\mathrm{X}$ are due to remaining protons in the monomeric units.

to the monomer can also be neglected. Then, the number of initiator fragments, 1.15 , means that $85 \%$ of polymer molecules are formed through disproportionation reaction and that half of them should contain double bond at the chain end.
Undeuterated MMA was polymerized in bulk at $60^{\circ} \mathrm{C}$ with AIBN (Table I, No. 5). The resultant polymer showed two small peaks in the olefinic proton region at 5.4 and $6.14 \mathrm{ppm}$ in $\mathrm{CDCl}_{3}$ at $55^{\circ} \mathrm{C}$ (Figure 2). The $T_{1} \mathrm{~s}$ for these peaks were about $0.5 \mathrm{~s}$.<smiles>C=C(CCCCCCCCCCCC(C)(C)C(=O)OC)C(=O)OC</smiles> 


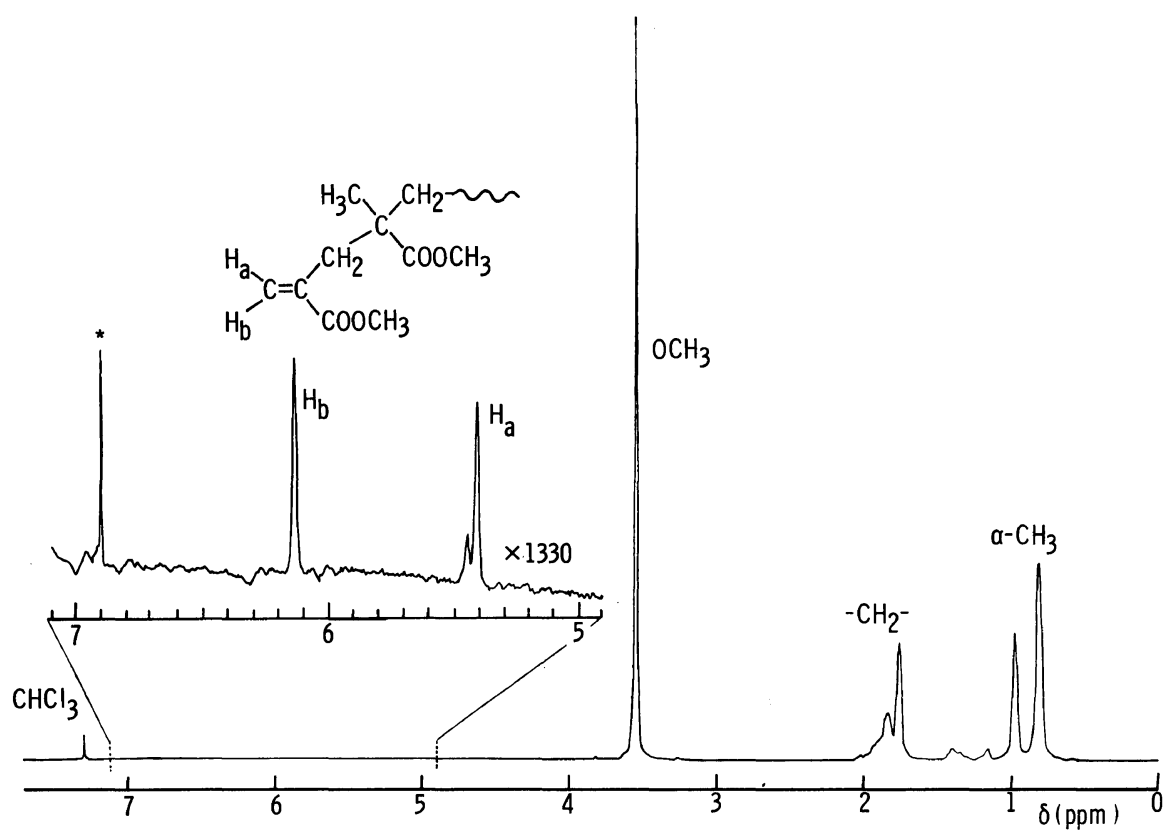

Figure 2. ${ }^{1} \mathrm{H}$ NMR spectrum of PMMA prepared with $\mathrm{AIBN}$ in bulk at $60^{\circ} \mathrm{C}\left(\mathrm{CDCl}_{3}, 55^{\circ} \mathrm{C}, 270 \mathrm{MHz}\right)$. ${ }^{*}{ }^{13} \mathrm{C}$ satellite band of $\mathrm{CHCl}_{3}$.

The vinylidene protons of MMA should show signals at 5.51 and $6.05 \mathrm{ppm}$ if they exist. Then the peaks at 5.4 and 6.14 ppm must be assigned to the methylene protons of the vinylidene group which was formed through the route $\mathrm{A}$ of the disproportionation reaction (eq 1). Similarly to the case of $\mathrm{MMA}^{23}$ the lowerand higher-field peaks were assigned to the protons cis and trans to the methoxycarbonyl group, respectively, on the basis of the deshielding effect of the carbonyl group. Further splitting of the latter peak may be due to the tacticity of the dyad at the chain end. Intensity measurement of the peaks indicates that $36 \%$ of the polymer molecules contain the vinylidene double bond at the chain end. Terminal olefinic methine proton, possibly formed through route $B$, is expected to show signals at 6.5-7.0 ppm.* However, no signals of appreciable intensity were observed in this region. Then, the results mentioned above mean that
$72 \%$ of the polymer molecules is formed through the disproportionation reaction. The difference between the results obtained from PMMA- $d_{8}$ and undeuterated PMMA may be partly due to the isotope effect in the termination reaction and partly due to the experimental error. It is also possible that a small amount of olefinic methine proton formed through route $B$ existed in the polymer chain but could not be detected by NMR owing to the lower signal intensity. The study on these points is now underway and will be published elsewhere.

Enikolopyan et al. reported that the polymerization of MMA with AIBN in the presence of cobalt-porphyrin derivative complexes produced the oligomer having a vinylidene group at the chain end. ${ }^{25} \mathrm{~A}$ higher molecular weight polymer of MMA was prepared according to Enikolopyan's procedure. MMA was polymerized with AIBN $(0.1 \mathrm{~mol} \%$ of

* Kimura et al. reported ${ }^{1} \mathrm{H}$ NMR data for a terminally unsaturated dimer, $\mathrm{CCl}_{3}-\mathrm{CH}_{2}-\mathrm{C}\left(\mathrm{CH}_{3}\right)\left(\mathrm{COOCH}_{3}\right)-\mathrm{CH}=$ $\mathrm{C}\left(\mathrm{CH}_{3}\right)\left(\mathrm{COOCH}_{3}\right)$; the chemical shift of the olefinic methine proton is $\delta=6.71 .^{24}$ 


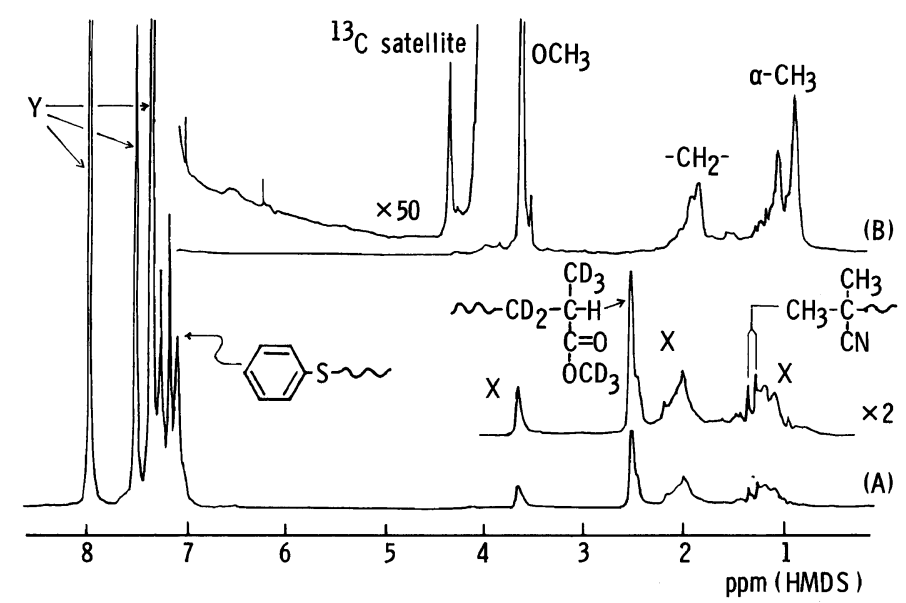

Figure 3. ${ }^{1} \mathrm{H}$ NMR spectra of (A) poly(MMA- $\left.d_{8}\right)$ and (B) PMMA prepared by AIBN in benzene at $60^{\circ} \mathrm{C}$ in the presence of thiophenol $\left(5 \mathrm{~mol} \%\right.$ of monomer) (nitrobenzene- $\left.d_{5}, 110^{\circ} \mathrm{C}, 100 \mathrm{MHz}\right) . \mathrm{X}$ and $\mathrm{Y}$ represent signals due to remaining protons in the monomeric units and solvent, respectively.

MMA) in the presence of cobalt-tetraphenylporphine complex $\left(2 \times 10^{-3} \mathrm{~mol} \%\right.$ of MMA $)$ at $60^{\circ} \mathrm{C}$. The resultant polymer $\left(M_{n}=11,600\right)$ showed vinylidene proton signals just the same as those observed in Figure 2. This is strong evidence for the assignment mentioned above.

Figure $3 \mathrm{~A}$ shows the ${ }^{1} \mathrm{H}$ NMR spectrum of the polymer of MMA- $d_{8}$ prepared with AIBN in benzene at $60^{\circ} \mathrm{C}$ in the presence of thiophenol. In the spectrum, there appear a multiplet due to the aromatic protons of a phenyl- thio group at $6.8-7.3 \mathrm{ppm}$ and the signal of the methine proton attached to the terminal MMA unit at $2.43 \mathrm{ppm}$. The signal due to the AIBN fragment at 1.23 and $1.31 \mathrm{ppm}$ was much weaker than the former two signals. The intensity measurements indicate that almost all the polymer molecules contain one phenylthio group and one terminal methine proton in each molecule (Figure 3A), that is, the polymer molecules form entirely through the chain transfer reaction to thiophenol.

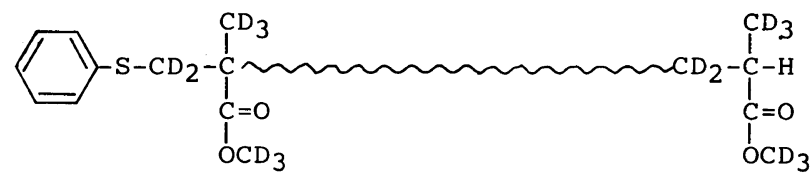

Undeuterated PMMA prepared under the same conditions gave no signals in the olefinic proton region in the spectrum (Figure 3B). This is additional clear evidence that the peaks at 5.4 and $6.14 \mathrm{ppm}$ in Figure 2 should be assigned to the vinyl methylene protons at the chain end.

PMMA- $d_{8}$ prepared in benzene with AIBN at $60^{\circ} \mathrm{C}$ was found to have $1.13_{5}$ initiator fragments per polymer molecule (Table I, No.
2). The chain transfer constant to the solvent is reported to be $0.4 \times 10^{-5}$ in the polymerization of MMA in benzene at $60^{\circ} \mathrm{C},{ }^{32}$ and the degree of polymerization of the PMMA- $d_{8}$ to be less than $4 \times 10^{2}$. The effect of the transfer reaction to benzene can thus be ignored. Then, the number of initiator fragments obtained here, $1.13_{5}$, is directly related to the relative importance of the disproportionation and combination reactions and indicates that $86.5 \%$ of 
Table II. Fraction $(N)$ of polymer molecules formed through disproportionation termination

\begin{tabular}{|c|c|c|c|c|c|}
\hline No. & Initiator & Solvent & $\frac{\text { Temp }}{{ }^{\circ} \mathrm{C}}$ & $\frac{N}{\%}$ & Lit. \\
\hline 1 & ${ }^{14} \mathrm{C}-\mathrm{AIBN}$ & Benzene & 0 & 75 & 2 \\
\hline 2 & ${ }^{14} \mathrm{C}$-AIBN & None & 25 & 84 & 1 \\
\hline 3 & ${ }^{14} \mathrm{C}$-AIBN & Benzene & 25 & 80 & 1 \\
\hline 4 & $\mathrm{Mn}_{2}(\mathrm{CO})_{10}-\mathrm{PVTCA}^{\mathrm{a}}$ & None & 25 & 80 & 26,27 \\
\hline 5 & ${ }^{14} \mathrm{C}$-AIBN & $?$ & 40 & 47 & 28 \\
\hline $6^{\mathrm{b}}$ & AIBN & None & 60 & 85 & This work \\
\hline $7^{\mathrm{b}}$ & AIBN & Benzene & 60 & 87 & This work \\
\hline $8^{b}$ & $\mathrm{BPO}$ & Benzene & 60 & 80 & This work \\
\hline 9 & ${ }^{14} \mathrm{C}$-AIBN & Benzene & 60 & 92 & 2 \\
\hline 10 & ${ }^{14} \mathrm{C}$-AIBN & $?$ & 60 & 60 & 28 \\
\hline 11 & ${ }^{14} \mathrm{C}-\mathrm{AIBN}$ & Benzene & 60 & 73 & 29 \\
\hline 12 & ${ }^{14} \mathrm{C}-\mathrm{AIBN}$ & None & 60 & 73 & 30 \\
\hline $13^{\mathrm{c}}$ & ${ }^{14} \mathrm{C}$-AIBN & None & 60 & 48 & 30 \\
\hline 14 & $\mathrm{Mn}_{2}(\mathrm{CO})_{10}-\mathrm{PVTCA}^{\mathrm{a}}$ & None & 60 & 84 & 26,27 \\
\hline 15 & ${ }^{14} \mathrm{C}$-AIBN & $?$ & 80 & 72 & 28 \\
\hline 16 & $\mathrm{Mn}_{2}(\mathrm{CO})_{10}-\mathrm{PVTCA}^{\mathrm{a}}$ & None & 80 & 89 & 26,27 \\
\hline 17 & $\mathrm{ACVA}^{\mathrm{d}}$ & $?$ & 90 & $\sim 100$ & 27,31 \\
\hline
\end{tabular}

a Poly(vinyltrichloroacetate).

b $\mathrm{CD}_{2}=\mathrm{C}\left(\mathrm{CD}_{3}\right) \mathrm{COOCD}_{3}$ was used.

c $\mathrm{CD}_{2}=\mathrm{C}\left(\mathrm{CD}_{3}\right) \mathrm{COOCH}_{3}$ was used.

d $\gamma, \gamma^{\prime}$-Azobis $(\gamma$-cyano- $n$-valeric acid $)$.

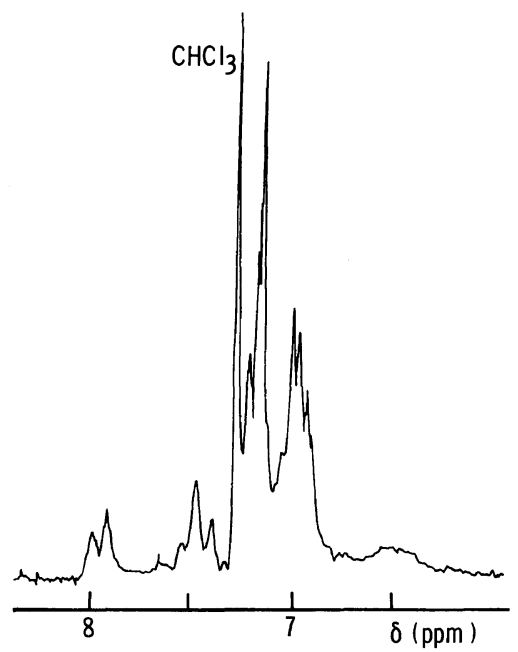

Figure 4. ${ }^{1} \mathrm{H}$ NMR spectrum of poly(MMA- $\left.d_{8}\right)$ prepared in benzene at $60^{\circ} \mathrm{C}$ with $\mathrm{BPO}\left(\mathrm{CDCl}_{3}, 55^{\circ} \mathrm{C}\right.$, $100 \mathrm{MHz}$ ).

the polymer molecules form through the disproportionation reaction similarly to the polymerization in bulk.
Polymerization of MMA- $d_{8}$ was carried out in benzene at $60^{\circ} \mathrm{C}$ with $\mathrm{BPO}$ at the initial monomer concentration of $0.91 \mathrm{moll}^{-1}$. The aromatic proton region spectrum of the resultant polymer in $\mathrm{CDCl}_{3}$ at $55^{\circ} \mathrm{C}$ is shown in Figure 4. These resonances should be assigned to the initiator fragment at the beginning of the chain since the polymer prepared with AIBN under the same conditions showed no signals in this region. The number of initiator fragments was calculated to be 1.20 , indicating again the predominance of disproportionation in the termination reaction (Table I). The value is slightly higher than that for the polymer prepared with AIBN. The difference may be attributable to the existence of transfer to BPO (transfer constant $=0.02)^{33}$ while transfer to AIBN is reported to be negligible. Among the resonances of BPO fragments, the signals at 7.95 and $7.3-7.6 \mathrm{ppm}$ were assigned to $o$ protons and $m$ - and $p$-protons of the benzoyloxy group, respectively, and the residual peaks 
to the phenyl group. The assignments were made by comparing the spectrum with those of model compounds such as methyl and ethyl benzoates. The relative number of benzoyloxy and phenyl groups at the beginning of the polymer chain was determined to be $18 / 82$ from the intensity measurements. Bevington and his coworker reported, using BPOs labeled by ${ }^{14} \mathrm{C}$ in different parts of the molecule, that the initiation was caused both by benzoyloxy and phenyl radicals in the polymerization of MMA in benzene at $60^{\circ} \mathrm{C}$ with BPO and the relative importance of the former to the latter becomes greater with increasing concentration of monomer. ${ }^{34}$ From their experimental data, the relative numbers of benzoyloxy and phenyl groups in the polymers prepared at the monomer concentration of $0.91 \mathrm{moll}^{-1}$ were estimated to be $21 / 79$; these are in good agreement with our results obtained by the NMR method (cf. Table I, No. 4).

In Table II, the results on the relative importance of disproportionation and combination reactions reported in previous papers are summarized together with those obtained in this work. Most of the data indicate the predominance of disproportionation termination in polymerizations in bulk or in benzene in the temperature range from 0 to $90^{\circ} \mathrm{C}$. However, it seems difficult to discuss these data in detail since the results obtained in the literatures were fairly scattered.

In conclusion, the predominance of disproportionation in the radical polymerization of MMA was demonstrated by analysis of initiator fragments using a totally deuterated monomer technique. This was also shown by analysis of unsaturated end groups in the polymer. Analysis of end groups should lead to a better understanding of the physical properties of polymers as well as the mechanism of polymerization. Our work is now being extended to polymerizations in various solvents and the results will be reported in the near future.

Acknowledgement. The authors are grate- ful to Dr. R. Miura of the National Cardiovascular Center for measuring some of the NMR spectra and Mrs. F. Yano for her clerial assistance in preparing this manuscript.

\section{REFERENCES}

1. J. C. Bevington, H. W. Melville, and R. P. Taylor, J. Polym. Sci., 12, 449 (1954).

2. J. C. Bevington, H. W. Melville, and R. P. Taylor, J. Polym. Sci., 14, 463 (1954).

3. J. C. Bevington, J. R. Ebdon, T. N. Huckerby, and N. W. E. Hutton, Polymer, 23, 163 (1982).

4. J. C. Bevington, T. N. Huckerby, and N. W. E. Hutton, J. Polym. Sci., Polym. Chem. Ed., 20, 2655 (1983).

5. G. Ayrey, K. Jumangat, J. C. Bevington, and T. N. Huckerby, Polym. Commun., 24, 275 (1983).

6. G. Moad, D. H. Solomon, S. R. Johns, and R. I. Willing, Macromolecules, 17, 1094 (1984).

7. G. Moad, D. H. Solomon, S. R. Johns, and R. I. Willing, Macromolecules, 15, 1188 (1982).

8. J. C. Bevington, T. N. Huckerby, and N. W. E. Hutton, Eur. Polym. J., 20, 525 (1984).

9. J. C. Bevington and T. N. Huckerby, J. Macromol. Sci.-Chem., A20, 753 (1983).

10. J. C. Bevington, T. N. Huckerby, and N. W. E. Hutton, Eur. Polym. J., 18, 963 (1982).

11. J. C. Bevington, T. N. Huckerby, and N. Vickerstaff, Makromol. Chem., Rapid Commun., 4, 349 (1983).

12. K. Hatada, T. Kitayama, and H. Yuki, Makromol. Chem., Rapid Commun., 1, 51 (1980).

13. K. Hatada, T. Kitayama, K. Fujikawa, K. Ohta, and H. Yuki, Polym. Bull., 1, 97 (1978).

14. K. Hatada, T. Kitayama, and E. Masuda, Polym. J., 17, 985 (1985).

15. K. Hatada, T. Kitayama, and H. Yuki, Polym. Bull., 2, 15 (1980).

16. K. Hatada, T. Kitayama, K. Fujikawa, K. Ohta, and H. Yuki, ACS Symp. Ser., 166, 327 (1981).

17. K. Hatada, T. Kitayama, S. Okahata, and H. Yuki, Polym. J., 13, 1045 (1981).

18. K. Hatada, T. Kitayama, S. Okahata, and H. Yuki, Polym. J., 14, 971 (1982).

19. K. Hatada, K. Ute, K. Tanaka, T. Kitayama, and Y. Okamoto, Polym. J., 17, 977 (1985).

20. J. W. C. Crawford, British Patent 405699 (1934).

21. K. Hatada, Y. Terawaki, and H. Okuda, Org. Magn. Res., 1, 518 (1977).

22. J-H. Fuhrhop and K. M. Smith, "Porphyrins and Metalloporphyrins," K. M. Smith, Ed., Elsevier Science Publishers, Amsterdam, 1975, p 798.

23. F. A. Bovey, "Nuclear Magnetic Resonance Spectroscopy," Academic Press, London, 1969, p 144.

24. T. Kimura, T. Kodaira, and M. Hamashima, Polym. 


\section{K. Hatada, T. Kitayama, and E. Masuda}

J., 15, 293 (1983).

25. N. S. Enikolopyan, B. R. Smirnov, G. V. Ponomarov, and I. M. Belgovskii, J. Polym. Sci., Polym. Chem. Ed., 19, 879 (1981).

26. C. H. Bamford, G. C. Eastmond, and D. Whittle, Polymer, 9, 771 (1969).

27. C. H. Bamford, R. W. Dyson, and G. C. Eastmond, Polymer, 10, 885 (1969).

28. G. V. Schulz, G. Henrich-Olivé, and S. Olivé, Makromol. Chem., 31, 88 (1959).

29. G. Ayrey and C. G. Moore, J. Polym. Sci., 36, 41
(1959).

30. G. Ayrey and D. J. D. Wong, Polymer, 16, 623 (1975).

31. C. H. Bamford and A. D. Jenkins, Nature, 176, 78 (1955).

32. R. N. Chandha, J. S. Shukla, and G. S. Misra, Trans. Faraday Soc., 53, 240 (1957).

33. G. Henrici-Olivé and S. Olivé, Fortschr. Hochpolym. Forsch., 2, 496 (1961).

34. J. C. Bevington, Proc. R. Soc. London, Ser. A, 239, 420 (1957). 